the hydrocarbon appears to be counteracted by the effect of the reduction in the rate of filtration brought about by the hydrophobic surface of the filter.

In addition to the errors introduced by this adsorption during filtration, particles of hydrocarbon (seen as bright fluorescent specks when the filtrates are viewed in ultraviolet light) occasionally pass through paper or sinteredglass filters. The centrifugation procedure of Kofahl and Lucas ${ }^{14}$ was found to give fairly reproducible results, even with viscous solutions of highly polymerized DNA. Two centrifugations, with 'Pyrex'-wool plugs centrifuged down on to the residue, were sufficient to ensure removal of suspended hydrocarbon. Comparison of the spectra of the resulting solutions and of the original suspensions, using the base-line technique, showed the change in concentration of the dissolved hydrocarbons to be less than 10 per cent during this procedure. By this method, considerably less variation is observed than when filtration is used to remove undissolved hydrocarbon. The loss may arise from adsorption on the centrifuge tubes and on the glasswool plugs.

This work was supported, in part, by the Division of Air Pollution, U.S. Public Health Service, Department of Health, Education and Welfare. I thank Dr. H. S. Isbell, Dr. R. S. Tipson and J. H. Gould for helpful discussions.

National Bureau of Standards, MAX N. INSCOE*

Washington, D.C.

* Present address: Entomology Research Division, Agricultural Research Service, U.S. Department of Agriculture, Beltsville, Maryland.

${ }^{1}$ Zimmerman, jun., H. K., Chem. Rev., 51, 25 (1952)-see p. 52.

2 Boyland, E., and Green, B., Brit. J. Cancer, 347 (1962).

s'Ts'o, P. O. P., and Lu, P., Proc. U.S. Nat. Acad. Sei., 51, 17, 272 (1964).

4 Boyland, E., and Green, B., J. Mol. Biol., 9, 589 (1964).

${ }^{5}$ Liquori, A. M., De Lerma, B., Ascoli, F., Botré, C., and Trasciatti, M., Boyland, $\mathrm{E}$, and Green, B.

Minney, L. E., and Heidelberger, C., J. Mol. Biol., 8

'Stauff, J., and Reske, G., Z. Naturforsch., 15 B, 578 (1960),

'Wayne, L. G., and Kidd, G. C., Amer. J. Clin. Path., 28, 495 (1957).

${ }^{10}$ Cooper, R. L., Analyst, 79, 573 (1954).

${ }^{11}$ Commins, B. T., A nalyst, 83, 386 (1958).

12 Weil-Malherbe, H., Biochem. J., 40, 351 (1946).

${ }^{13}$ Munck, A., Biochim. Biophys. Acta, 24, 507 (1957).

${ }^{14}$ Kofahl, R. E., and Lucas, H. J., J. Amer. Chem. Soc., 76, 3931 (1954).

\section{X-ray Fluorescence Analysis of Heavy Elements in a Light Matrix}

WHEN solids or liquids are irradiated with $\mathrm{X}$-rays the elements in the substance emit secondary fluorescent radiation. The intensity of the fluorescent radiation

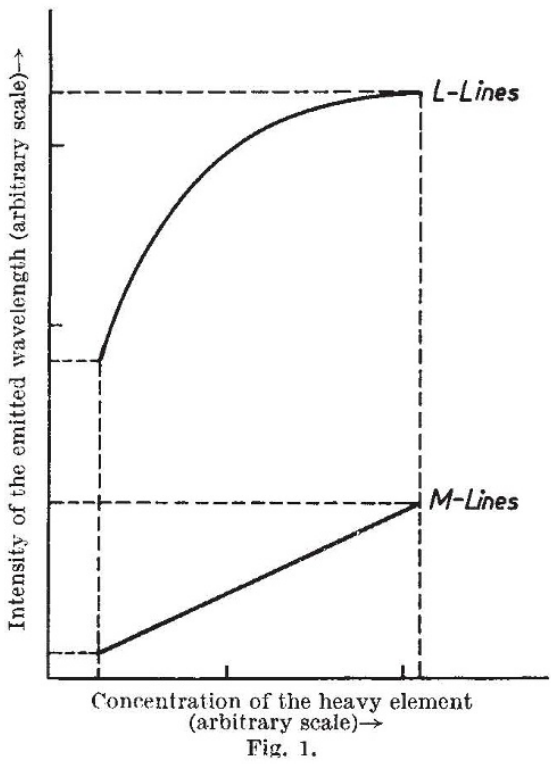

from an element in a mixture is usually not proportional to the concentration of that element. The reason for this is that the heavy element exhibits an X-ray absorption markedly different from the matrix. Thus a plot of the intensity of the emitted wavelength $(L$ line) against concentration of the heavier element in the mixture gives a curve which, as the concentration of the element increases, becomes parallel to the concentration axis (Fig. $1 L$ ).

Addink, Kraay and Witmer ${ }^{1}$ have shown that by adding quantities of strongly absorbing material, a linear relationship can be effected between the intensity and concentration; however, special considerations are required when the results so obtained are interpreted. The same effect can be accomplished by making intensity measurements at a longer wavelength when the absorption in the heavy element and matrix is more or less equal (Fig. 1M). Under these conditions, the analysis resembles the measurement of the concentration of a light element in a light matrix. Thus, for example, when the concentration of lead in silicates is determined by this technique it is the intensity of the $\mathrm{PbM} \alpha_{1}, 2$ line which is measured instead of the usual $\mathrm{PbL} \alpha_{1}$, and when the concentration of bismuth in sodium carbonate is determined it is the $\operatorname{Bi} M \alpha_{1,2}$ line and not the $\operatorname{Bi} L \alpha_{1}$.

T. Groot

P. C. M. N. BruiJs

J. H. T. C. VERBEEK

Philips Research Laboratories,

N.V. Philips' Gloeilampenfabrieken,

Eindhoven, The Netherlands.

${ }^{1}$ Addink, N. W. H., Kraay, H., and Witmer, A. W., Ninth Colloq. Spectros. Intern., 3, 368 (1961).

\section{Extension of the Periodic Table}

In the course of an investigation concerning the behaviour of orbital objects around a nucleus, in which the properties of various simple theoretical models were studied to determine under what conditions the exchange of radiation and/or particles obeying the "inverse square law" could account for other interaction laws (not necessarily only at the nuclear or atomic level), the following series was found:

$$
\frac{n_{1}}{1^{2}}+\frac{n_{2}}{2^{2}}+\frac{n_{3}}{3^{2}}+\ldots \ldots=2 k \quad(k=1,2,3, \text { etc. })
$$

It arose in more than one model, and is of little significance to the more ambitious main investigation. For example, the factor " 2 " in the right-hand side is to be expected whenever certain conditions of symmetry are postulated: and the left-hand side occurs at once when considering the "classical" potential energy of " $n_{r}$ " electrons in the " $r$ "-th Bohr orbit"; and also in other models (for example, in which the radius of the " $r$ "-th orbit is proportional to " $r$ " and "inverse square law" attractions are summed).

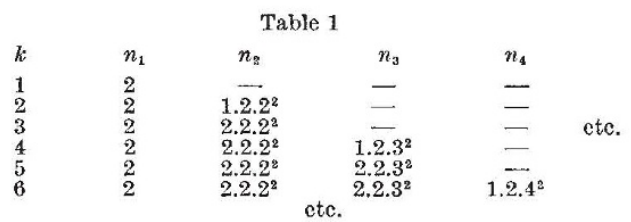

From the infinite number of solutions of this equation, however, the regular pattern of solutions given in Table 1 is highly suggestive.

In the original investigation, the " $n_{1}$ ", " $n_{2}$ ", etc., referred to the number of orbital objects in successively remote orbits from the nucleus, and the regular pattern of solutions already given tallies precisely with the gross electron structures of the noble gases ${ }^{2}$ as shown in Table 2. 